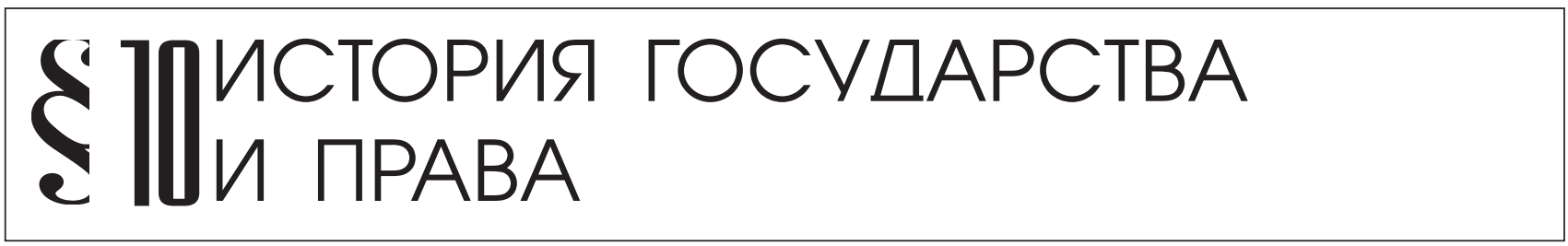

Биюшкина Н.И.

\title{
СРАВНИТЕЛЬНО-ПРАВОВОЙ АНАЛИЗ ЗАКОНОДАТЕЛЬСТВА ОБ ИСКЛЮЧИТЕЛЬНОМ ПОЛОЖЕНИИ В РОССИИ И ЗА РУБЕЖОМ ВО ВТОРОЙ ПОЛОВИНЕ ХІХ в.
}

Аннотация: Статья посвящена сравнительно-правовому анализу такого неоднозначного понятия в теории государства и права, как исключительное положение. Рассматривается процесс разработки и принятия Положения «О мерах к охранению государственного порядка и общественного спокойствия» от 14 августа 1881 г. Эта юридическая конструкиия являлась ключевой в рамках внутриполитического охранительного курса Российского государства в изучаемый период. В статье раскрывается цель применения исключительного положения, его понятие, основные признаки, проводится сравнительно-правовая характеристика с аналогичными правовыми конструкииями в зарубежном законодательстве. В настоящей работе используются методы сравнительноправового анализа, ретроспективный, догматический с иелью детального изучения правового регулирования исключительного положения в России и в Западной Европе во второй половине ХІХ в. Впервые в ракурсе сравнительно-правового анализа исследуются общие и особенные черты правового регулирования исключительного положения в России и в Западной Европе в изучаемый период. Детально изучаются процессы формирования и функционирования законодательства об исключительном положении. Определяется роль видных российскихгосударственных и общественных деятелей в разработке и принятии Положения «О мерах к охранению...» от 14 августа 1881 г. и других нормативно-правовых актов, регламентировавших режим исключительного положения. Ключевые слова: Исключительное положение, охранительный курс, сравнительно-правовой анализ, Комитет Министров, чрезвычайное правовое регулирование, чрезвычайные обстоятельства, полицейское право, административная власть, права подданных, чрезвычайная охрана.

Abstract: This article is dedicated to the comparative legal analysis of such ambiguous concept within the theory of state and law as state of exception. The author examines the process of development and passing the bill "On Measures to Protect State Security and Public Peace" from August 14, 1881. This was the key legal construct within the framework of domestic political safety course of the Russian state during this period. The article explains the purpose of implementing the state of exception, its concept, main aspects, and presents the comparative legal characteristics with similar legal constructs in foreign legislation. The author gives a detailed analysis to the processes of formation and functionality of the legislation on state of exception, determines the role of noted Russian state and public actors in development and passing of the bill in August of 1881, as well as other normative legal acts that regulated the regime of state of exception. Keywords: State of exception, Security course, Comparative legal analysis, Committee of Ministers, Exceptional legal regulation, Exceptional circumstances, Administrative law, Administrative authority, Citizen rights, Emergency security.

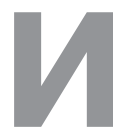

нститут исключительного положения был веден в правовую систему Российской империи во время правления Александра III Положением «О мерах к охранению государственного порядка и общественного спокойствия» от 14 августа 1881 г. [3]. Этот нормативно-правовой акт - ключевой источник права, регулирующий охранительные отношения, сформировавшиеся в период правления Александра III при деятельном участии его ближайших соратников: К.П. Победоносцева[5], М.Н. Каткова, В.П. Мещерского и др. Положение было составлено Особой комиссией под председательством статс-секретаря М.С. Каханова и представлено на рассмотрение Комитета Министров. При рассмотрении проекта Комитетом в Положение были внесены лишь незначительные изменения. В частности, были несколько ограничены полномочия 
DOI: $10.7256 / 1811-9018.2015 .10 .14992$

При цитировании этой статьи сноска на dоі обязательна

\section{Право и политика $10(190) \cdot 2015$}

министра внутренних дел в виде обязания представлять всеподданнейшие доклады о неотложно принятых им мерах (например, об отмене постановлений генерал-губернаторов следовало довести до сведения Комитета Министров). Предоставленное изначально главноначальствующим местностей, объявленных в исключительном положении, право устранять от должности чиновников всех ведомств, было несколько ограничено обязанностью испрашивать на это разрешения министра внутренних дел и входить с особыми представлениями в Комитет Министров.

Основными целями издания Положения явились: искоренение «гнусной крамолы», позорящей землю Русскую, утверждение веры и нравственности, доброе воспитание детей, истребление неправды и хищения, водворение порядка и правды в действии учреждений, дарованных России Александром II [1].

Большую ценность для изучения законодательных актов чрезвычайного характера представляют легализованные императорским указом от 4 сентября 1881 г. принципы чрезвычайного правового регулирования, заложенные в Положении «О мерах к охранению...» от 14 августа 1881 г.:

- соразмерность пространства особых полномочий властей, поставленных на страже общественного порядка, с ответственностью, возлагаемою на них исключительными обстоятельствами времени;

- временный характер исключительных мер;

- соответствие исключительных мер действительной потребности охранения порядка, недопустимость излишнего отягощения законных интересов верного престолу населения.

В теории дополнительно выделяют также принципы: чрезвычайности обстоятельств (наступление своеобразных, т.е. явно выделяющихся среди других моментов государственной жизни, необычных, т.е. значительно отклоняющихся от нормального течения государственной жизни, и временных по своему характеру обстоятельств), необходимости в мере (недостаточность законных средств для ответа на чрезвычайные обстоятельства, неотложная потребность в издаваемой мере, причинная связь между издаваемой мерой и чрезвычайными обстоятельствами) [13. С. 55 - 80].

Таким образом, как говорится в императорском Указе от 4 сентября 1881 г., «усматривая, что в изданных разновременно узаконениях для облегчения борьбы с крамолой, сущность и пределы полномочий административных начальств указаны не с достаточною в сем отношении определительностью, МЫ сочли за благо повелеть, подвергнув совокупному пересмотру все вре- менные законы, изданные в последнее время, начертать взамен сих узаконений, особое положение, в котором были бы указаны, с большею чем ныне точностью, с одной стороны пределы полномочий административных начальств при чрезвычайных обстоятельствах, a c другой - сущность обязанностей, возлагаемых на население исключительными обстоятельствами государственной жизни».

Составленный Особо учрежденной Комиссией Проект Положения «О мерах к охранению государственного порядка и общественного спокойствия» по предварительному рассмотрению его в Комитете Министров был утвержден высочайшей законодательной властью императора 14 августа 1881 г. и введен в действие 4 сентября 1881 г. Впоследствии Положение «О мерах к охранению...» от 14 августа 1881 г. было включено в Устав о предупреждении и пресечении преступлений по прод. 1883 г. в качестве приложения 1 к примечанию 2 к ст. 1[2].

Положение оперирует термином «исключительное положение», определяя его основные признаки: расширение круга обязанностей и пределов власти существующих административных установлений по охранению государственного порядка и общественной безопасности, а равно возложение таковых чрезвычайных полномочий временно учреждаемым для этой цели правительственным органам при одновременном усилении ответственности как частных, так и административных властей за неисполнение обязанностей, на них возложенных. Исследователь В.М. Гессен представляет понятие исключительного положения в широком смысле как «совокупность исключительных полномочий, в чем бы они не состояли, предоставляемых правительственной власти, при наступлении обстоятельств, угрожающих изнутри или извне существования государства» $[10$. C. 74]. При этом он рассматривает в качестве исключительного положения военное (или осадное) в собственном смысле этого слова, вводимое в случае внешней войны, и фиктивное военное положение, вводимое в случае внутренних смут [10. С. 154]. В своей позиции B.M. Гессен придерживается опыта французского исключительного законодательства, где также в то время выделялось действительное и фиктивное положение: «первое вводилось в случаях внешней войны, второе - «в случае восстания с оружием в руках» [10. С. 154].

Таким образом, исключительное положение, регулируемое Положением «О мерах к охранению...» от 14 августа 1881 г., относится ко второму виду общей категории, выделенной В.М. Гессеном. Похожая точка зрения представлена Н.Н. Белявским, он также выделя- 
DOI: $10.7256 / 1811-9018.2015 .10 .14992$

При цитировании этой статьи сноска на dоі обязательна

История государства и права

ет военное и осадное положение, которые вводятся при условии недостаточности мер общей гражданской полиции и сводятся к ограничению гражданской свободы при расширении администрации в целях подавления преступных посягательств [4. С. 91].

Существует и узкое понимание «исключительного положения», которого придерживается большинство исследователей в области полицейского права. В частности, И.Т. Тарасов, противопоставляет его «военному положению»: существенным отличием исключительного и военного положения является то, что «в первом случае усиливается власть полиции и администрации, во втором же случае полиция и администрация подчиняются военной власти, в руках которой сосредотачивается управление» [15. С. 93]. Л. Штейн также выделяет чистое понятие «исключительное положение», приводя при этом совокупность его качественных признаков: 1) объявление исключительного положения исходит от административного управления, в обязанности которого входит обеспечение публичной безопасности, по предварительному соглашению с высшим органом правосудия (если же таковое не последовало, то окончательное разрешение вопроса зависит от министра внутренних дел); 2) объявление носит характер формальный и публичный; 3) исключительное положение должно распространяться только на те преступления, которые ввиду частого повторения вызвали необходимость его введения; 4) установление новой, более строгой системы наказаний; 5) криминализация деяний, ранее не являвшихся наказуемыми, но представляющих опасность в условиях сложившейся обстановки; 6) ужесточение правил печати; 7) полицейские действия должны распространяться только на определенные преступления, объявленные подсудными чрезвычайным судам (не обязательно военным, но во всяком случае без участия присяжных заседателей); 8) при общем принципе неприкосновенности прав отдельных лиц, полиция уполномочивается на совершение обысков, выемок, наложение арестов, запрещений и т.п. без предварительного судебного разрешения [14. С. 152].

Л. Штейн также проводит разграничение военного и исключительного положения, представляя при этом более полный ряд отличительных критериев: 1) военное положение объявляется при возникновении внешней опасности со стороны враждебной вооруженной силы; 2) вводится только в определенной местности, где налицо явная угроза нападения; 3) все административные органы продолжают выполнять свои обязанности в той степени, в какой они не переданы военным органам; 4) при военном положении полномочия по изданию обязательных к исполнению предписаний переходят от полиции к военной власти; 5) в административном порядке полицейские органы безусловно подчиняются военным; 6) дела о неисполнении военных предписаний подведомственны военному суду; 7) военные власти наделяются правом приостанавливать деятельность различных государственных и общественных учреждений, управлений; 8) обжалование действий военной власти возможно только в административном порядке, в вышестоящий орган, но не в судебном [14. С. 152 - 153].

Исследователи, занимавшиеся разработкой вопроса исключительного положения, отмечали, что в зарубежном законодательстве наиболее ярким примером чрезвычайной меры безопасности является приостановление действия Habeas Corpus Act - основного гаранта прав личности в Англии [11. С. 150]. В.М. Гессен отмечает, что первый акт о его приостановке 1689 г. носил название «Акт об уполномочении его величества задерживать и подвергать заключению тех лиц, которых он будет иметь основательную причину подозревать в злоумышлениях против правительства», который заключался в том, что лица, задержанные по подозрению в государственной измене в силу приказа королевского Тайного Совета, подписанного, по крайней мере, шестью его членами, подлежали содержанию под стражей без права освобождения под обеспечение или поручительство до прекращения срока приостановки [10. С. 142]. Таким образом, отличительные особенности английского чрезвычайного законодательства заключаются: 1) в его выборочном характере (его действие распространяется только на право продолжительного задержания лиц, подозреваемых в причастности к государственным преступлениям), 2) отсутствие специального закона, предусматривающего полномочия административной власти при наступлении исключительных обстоятельств, 3) в предоставлении чрезвычайных полномочий административной власти т.н. законом $\mathrm{ad}$ hoc, т.е. отдельно, в каждом конкретном случае.

В отличие от этого, как отмечает В.М. Гессен, странам континентальной системы права присущи абсолютно противоположные черты исключительного законодательства. Для него характерно наличие постоянно действующего нормативно-правового акта, определяющего состав чрезвычайных полномочий власти на случай наступления экстраординарных обстоятельств, т.е. «государству не приходится изыскивать средств для борьбы с ними», эти средства уже установлены законодательством [10. С. 149]. Вопрос лишь заключается в том, какая власть - исполнительная или законодательная - уполномочена давать оценку 
DOI: $10.7256 / 1811-9018.2015 .10 .14992$

При цитировании этой статьи сноска на dоі обязательна

\section{Право и политика $10(190) \cdot 2015$}

обстоятельствам и квалифицировать их как исключительные, угрожающие государственному порядку и общественной безопасности. В отношении данного аспекта в странах романо-германской правовой системы существуют разные подходы. Во Франции законом 1848 г. осадное положение могло быть объявлено только парламентским законом, в случае перерыва сессии парламента осадное положение могло быть объявлено президентом республики согласно с мнением органа исполнительной власти - Совета Министров, но при этом парламент созывался в течение двух дней с даты объявления осадного положения, «по собственному праву», т.е. без созыва президентом [10. С. 150]. При роспуске парламента и до завершения избирательной процедуры осадное положение могло быть объявлено президентом республики согласно мнению Совета Министров только в случае войны с иностранным государством и строго на территории, которой угрожает вторжение неприятеля. При этом президент был обязан созвать избирательные коллегии и затем - палаты депутатов в кратчайший срок.

Н.Н. Белявский в своем труде описывает более поздний французский закон от 1878 г., которым осадное положение могло быть объявлено в случае непосредственно угрожающей опасности, возникающей вследствие внешней войны или вооруженного восстания [4. C. 92]. Оно также вводилось законодательной властью, на определенный срок и в строго оговоренной местности. Таким образом, французское законодательство в вопросе ограничения индивидуальных прав и свобод при наступлении чрезвычайных обстоятельств идет строго по пути сохранения приоритета за законодательной [6. С. 152] властью, в целях предупреждения возможного произвола со стороны администрации.

В отличие от представленной французской модели, в Германии, напротив, полномочие по объявлению осадного положения предоставлено административной власти в лице императора [10. С. 153]. В 1878 г. в Германии был принят закон «против опасных стремлений социал-демократов», который вводил в некоторых местностях империи т.н. «малое осадное положение», которое заключалось в частичном ограничении прав и свобод германских подданных, проживавших на территориях, которым угрожала опасность распространения социалистических течений, выражавшиеся, в частности, в следующем: 1) допущение любых собраний только с предварительного разрешения местной полицейской власти; 2) выпуск печатных произведений в разносную торговлю также допускался только с разрешения полицейской власти; 3) лица, представ- лявшие опасность для общественного спокойствия и государственной безопасности подлежали высылке из местностей, в которых было введено осадное положение; 4) устанавливались специальные нормы, регламентировавшие порядок реализации, ношения и хранения оружия [4. С. 92].

Неким промежуточным вариантом среди двух представленных является австрийская система, в которой приостановление конституционных гарантий прав личности утверждалось императорским декретом под коллективной ответственностью правительства, которое немедленно после созыва палат парламента представляло отчет в предпринятых мерах, их необходимости и адекватности.

Законодательная регламентация мер исключительного положения на будущее время, принятая в странах континентальной системы права, предполагает необходимость разработки унифицированной системы определения критерия исключительности обстоятельств, наступление которых может оправдывать введение соответствующих ограничений конституционных прав и свобод личности. Наиболее четкое законодательное определение данных критериев является важнейшим гарантом от необоснованного, неадекватного стеснения прав граждан. Так, по действовавшему тогда французскому закону 1878 г. осадное положение могло быть объявлено только в случаях неминуемой опасности, исходившей от внешней войны или вследствие вооруженного восстания. В Германии по закону от 4 июня 1851 г. осадное положение вводилось, помимо начала военных действий, также «в случаях восстания при крайней опасности, угрожающей общественному спокойствию». В Австрии - в случае внутренних беспорядков, или даже «значительного распространения изменнической пропаганды, угрожающей государственному строю или безопасности граждан» [10. С. 153].

Классическое содержание состояния исключительного положения представлено во французском законодательстве: 1) все полномочия по охране безопасности и порядка всецело концентрируются в руках военной власти; 2) данные полномочия носят полицейский характер и своим последствием имеют ограничение индивидуальной свободы в различных ее проявлениях (проводить обыски в жилых помещениях в любое время дня и ночи, выдворять из местности, находящейся на осадном положении, подсудимых граждан и не имеющих права постоянного проживания, требовать сдачи оружия и боеприпасов, запрещать определенные печатные издания, пресекать собрания, нарушающие порядок и общественное спокойствие и т.п.); 3) все 
DOI: $10.7256 / 1811-9018.2015 .10 .14992$

При цитировании этой статьи сноска на dоі обязательна

История государства и права

преступления, направленные против государственной безопасности, общественного порядка и спокойствия, передаются на рассмотрение военных судов приказом главнокомандующего, в обязательном порядке - дела о государственной измене, шпионстве и иные, направленные на ослабление вооруженных сил, все остальные - в факультативном порядке [10. С. 155 - 156].

В рассматриваемом Положении «О мерах к охранению...» от 14 августа 1881 г. выделяется два возможных состояния исключительного положения: усиленная охрана и чрезвычайное положение, которые различаются между собой по основаниям введения, степени ограничений прав и свобод, порядку административного управления. Об этом дуализме пишет, в частности, исследователь В.В. Ивановский, подчеркивая, что «русское законодательство знает два вида исключительного положения: 1) усиленную охрану, 2) чрезвычайную охрану» [12. С. 363]. Чрезвычайное положение определено им как «чрезвычайная охрана» вероятно потому, что введение исключительного положения преследует охранительную цель и заключается в усилении мер юридической ответственности всех субъектов общественных отношений, в т.Ч. государственных органов и должностных лиц.

\section{Библиография:}

1. Манифест «О призыве всех верных подданных к служению верою и правдой Его Императорскому Величеству и Государству» от 29 апреля 1881 г. Ст. 118 // ПСЗРИ. Изд. 3-е. - СПб.: Тип. Втор. Отд. Собств. Его Имп. Вел. Канц., 1885. Т. І.

2. Устав о предупреждении и пресечении преступлений // Продолжение Свода законов Российской империи по 30 июня 1883 г. Ч. 2. - СПб.: Гос. тип., б.г. - прилож. 1 к прим. 2 ст. 1.

3. Положение Комитета Министров «О мерах к охранению государственного порядка и общественного спокойствия» от 14 августа 1881 г. Ст. 350 // ПСЗРИ (Полное собрание законов Российской Империи). Изд. 3-е. - СПб., 1885. Т. I.

4. Белявский Н.Н. Полицейское право (Административное право). Конспект лекций. Изд. 2 е. - Юрьев: Тип. К. Маттисена, 1910. $-372 \mathrm{c}$.

5. Биюшкина Н.И., Победоносцев К.П. Консервативный национализм или умеренный реформизм//Актуальные проблемы российского права. 2009. № 3 (12). С. $62-68$.

6. Биюшкина Н.И. Политико-правовые взгляды Н.Х. Бунге//История государства и права. 2010. №1. С. 37 - 39.

7. Биюшкина Н.И. Правовой статус поднадзорных лиц в конце XIX века//Вестник Академии права и управления. 2011. №22. С. 107 - 113 .

8. Биюшкина Н. И. Проведение судебной реформы 1864 г. в российском государстве (на примере Нижегородской губернии): автореф. дис. ... канд. юрид. наук: Н. Новгород, 1998. - с.

9. Биюшкина Н. И. Проведение судебной реформы 1864 г. в российском государстве (на примере Нижегородской губернии): дис. ... канд. юрид. наук: Н. Новгород, 1998. - 261 с.

10. Гессен В.М. Исключительное положение. - СПб.: Изд. Юридического книжного склада «Право», $1908 .-410$ с.

11. Дерюжинский В.Ф. Habeas-Corpus акт и его приостановка по английскому праву. Очерк основных гарантий личной свободы в Англии и их временного ограничения. - Юрьев (б. Дерпт): Типо-лит. Г. Лакмана, 1895. - 392 с.

12. Ивановский В.В. Учебник административного права (Полицейское право. Право внутреннего управления) /// Российское полицейское (административное) право: конец XIX - начало XX века; Хрестоматия /Сост. Ю.Н. Старилов. - Воронеж: изд. Воронежского гос. унив-та, 1999. - С. 285 - 370

13. Магазинер Я.М. Чрезвычайно-Указное право в России (ст. 87 Осн. Зак.). - СПб.: Тип. М.М. Стасюлевича, 1911. - 173 с.

14. Тарасов И.Т. Основные положения Лоренца Штейна по Полицейскому праву в связи с его учением об управлении. - Киев: Университетская тип., 1874. - 235 с.

15. Тарасов И.Т. Учебник науки полицейского права. Вып. 1. - М.: Тов. «Печатня С.П. Яковлева», 1891. - 364 с.

16. Шмидт Т.Н. Теоретико-правовое обоснование чрезвычайного правового регулирования и доктрина «исключительного положения» // Политика и Общество. - 2013. - 9. - С. 1132 - 1140. DOI: 10.7256/1812-8696.2013.9.9482.

\section{References (transliterated):}

1. Belyavskii N.N. Politseiskoe pravo (Administrativnoe pravo). Konspekt lektsii. Izd. 2 e. - Yur'ev: Tip. K. Mattisena, 1910. - 372 s.

2. Biyushkina N.I., Pobedonostsev K.P. Konservativnyi natsionalizm ili umerennyi reformizm//Aktual'nye problemy rossiiskogo prava. 2009. № 3 (12). S. $62-68$.

3. Biyushkina N.I. Politiko-pravovye vzglyady N.Kh. Bunge//Istoriya gosudarstva i prava. 2010. №1. S. 37 - 39.

4. Biyushkina N.I. Pravovoi status podnadzornykh lits v kontse XIX veka//Vestnik Akademii prava i upravleniya. 2011. №22. S. $107-113$.

5. Biyushkina N. I. Provedenie sudebnoi reformy 1864 g. v rossiiskom gosudarstve (na primere Nizhegorodskoi gubernii) : avtoref. dis. ... kand. yurid. nauk: N. Novgorod, 1998. - s. 
DOI: 10.7256/1811-9018.2015.10.14992

При цитировании этой статьи сноска на dоі обязательна

\section{Право и политика $10(190) \cdot 2015$}

6. Biyushkina N. I. Provedenie sudebnoi reformy $1864 \mathrm{~g}$. v rossiiskom gosudarstve (na primere Nizhegorodskoi gubernii) : dis. ... kand. yurid. nauk: N. Novgorod, 1998. - $261 \mathrm{~s}$.

7. Gessen V.M. Isklyuchitel'noe polozhenie. - SPb.: Izd. Yuridicheskogo knizhnogo sklada «Pravo», $1908 .-410 \mathrm{~s}$.

8. Deryuzhinskii V.F. Habeas-Corpus akt i ego priostanovka po angliiskomu pravu. Ocherk osnovnykh garantii lichnoi svobody v Anglii i ikh vremennogo ogranicheniya. - Yur'ev (b. Derpt): Tipo-lit. G. Lakmana, 1895. - 392 s.

9. Ivanovskii V.V. Uchebnik administrativnogo prava (Politseiskoe pravo. Pravo vnutrennego upravleniya) /// Rossiiskoe politseiskoe (administrativnoe) pravo: konets XIX - nachalo XX veka; Khrestomatiya /Sost. Yu.N. Starilov. - Voronezh: izd. Voronezhskogo gos. univ-ta, 1999. - S. $285-370$

10. Magaziner Ya.M. Chrezvychaino-Ukaznoe pravo v Rossii (st. 87 Osn. Zak.). - SPb.: Tip. M.M. Stasyulevicha, 1911. - 173 s.

11. Tarasov I.T. Osnovnye polozheniya Lorentsa Shteina po Politseiskomu pravu v svyazi s ego ucheniem ob upravlenii. - Kiev: Universitetskaya tip., 1874. $-235 \mathrm{~s}$.

12. Tarasov I.T. Uchebnik nauki politseiskogo prava. Vyp. 1. - M.: Tov. «Pechatnya S.P. Yakovleva», 1891. - 364 s.

13. Shmidt T.N. Teoretiko-pravovoe obosnovanie chrezvychainogo pravovogo regulirovaniya i doktrina «isklyuchitel'nogo polozheniya» // Politika i Obshchestvo. - 2013. - 9. - C. 1132 - 1140. DOI: 10.7256/1812-8696.2013.9.9482. 